\title{
Compatibility of Diborane and Borane with FOX-7 - A DFT Treatment
}

\section{Lemi Türker}

Department of Chemistry, Middle East Technical University, Üniversiteler, Eskişehir Yolu No: 1, 06800 Çankaya/Ankara, Turkey; e-mail: lturker@gmail.com; lturker@metu.edu.tr

\section{Abstract}

\begin{abstract}
FOX-7 as an energetic material is getting more and more popular as the constituents of various ammunitions. On the other hand, boronic species attract attention as fuels in rocket engineering. The present study, within the constraints of density functional theory, considers some composites of them, that is $\mathrm{FOX}-7+\mathrm{B}_{2} \mathrm{H}_{6}, \mathrm{FOX}-7+2 \mathrm{BH}_{3}$ and $\mathrm{FOX}-$ $7+\mathrm{BH}_{3}$. The calculations at the B3LYP/6-311++G(d,p) level indicate that all the components are structurally stable in the composites although they interact with each other electronically. Various quantum chemical and QSAR data are obtained and discussed.
\end{abstract}

\section{Introduction}

Diborane is an interesting compound having the formula of $\mathrm{B}_{2} \mathrm{H}_{6}$ in which two threecentered bonds exist [1]. It is a gas (m.p. $-165.5^{\circ} \mathrm{C}$, b.p. $-92.5^{\circ} \mathrm{C}$ ) and stable up to $100^{\circ} \mathrm{C}$ $[2,3]$. All the evidence indicates that it is a diamagnetic material hence the molecule contains no unpaired electrons. The molecule is electron deficient, reacts with ammonia and certain amines and hydrazine [2-5]. In its structure each boron atom is tetrahedrally hybridized [6-8].

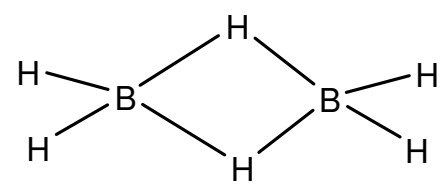

\section{Received: July 17, 2020; Accepted: August 9, 2020}

Keywords and phrases: DADNE, FOX-7, diborane, borane, explosive.

Copyright (C) 2020 Lemi Türker. This is an open access article distributed under the Creative Commons Attribution License, which permits unrestricted use, distribution, and reproduction in any medium, provided the original work is properly cited. 
On heating diborane produces borane [9]

$$
\mathrm{B}_{2} \mathrm{H}_{6} \rightleftharpoons 2 \mathrm{BH}_{3}
$$

Some theoretical studies exist in the literature on borane and diborane [10-12]. Liao elucidated the electronic structure of the hydrogen-bridge bond in $\mathrm{B}_{2} \mathrm{H}_{6}$ molecule. The decomposition product $\mathrm{BH}_{3}$ initiates hydroboration reactions which serve not only as an important preparation method for organoboron compounds but also as the first step in several reaction sequences of wide application in synthetic organic chemistry [6]. Hydroboration with diborane in the absence of catalytic ether solvents has not proved convenient for the preparation of organoboron compounds [6].

Diborane is used as a reducing agent, as a rubber vulcanizer, as a catalyst for hydrocarbon polymerization, as a flame-speed accelerator, and as a doping agent. It is also used in electronics to impart electrical properties in pure crystals [4-6, 13]. During 1950s, a considerable effort was expended in the search for diborane and organoboranes that could serve as efficient and easy-to-handle high-energy rocket propellants [14-18].

On the other hand, 1,1-diamino-2,2-dinitroethylene (DADE, DADNE) is an insensitive high explosive known as FOX-7 [19-21]. Many researchers have investigated its explosive potential thoroughly [22-36].

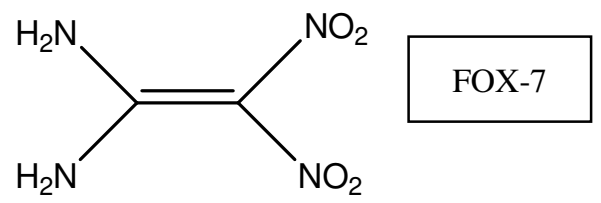

Nitration of 4,6-dihydroxy-2-methylpyrimidine and then hydrolysis constitutes an alternative route to FOX-7 [37]. It is a push-pull type molecule having donor and acceptor groups in its structure (amino and nitro groups, respectively) and exhibits abundant chemical reactivity including coordination reactions, nucleophilic substitutions, acetylate reactions, oxidation and reduction reactions, electrophilic addition reactions etc., [38, 39]. FOX-7 is much less sensitive than RDX (in terms of impact, friction, and electrostatic discharge sensitivities) [40]. In the last couple of decades several FOX-7 based propellant formulations have been developed in order to obtain propellant composites having a minimum or reduced smoke production [41]. 
In the present study, within the restrictions of density functional theory, some composites that is $\mathrm{FOX}-7+\mathrm{B}_{2} \mathrm{H}_{6}, \mathrm{FOX}-7+2 \mathrm{BH}_{3}$ and $\mathrm{FOX}-7+\mathrm{BH}_{3}$ are considered.

\section{Method of Calculation}

In the present study, the initial structural optimizations of all the structures leading to energy minima have been achieved by using MM2 method followed by semi-empirical PM3 self-consistent fields molecular orbital (SCF MO) method [42, 43] at the restricted level [44, 45]. Subsequent optimizations were achieved at Hartree-Fock level using various basis sets. Then, the structural optimizations were managed within the framework of density functional theory (DFT) [46, 47] at the level of B3LYP/6$311++\mathrm{G}(\mathrm{d}, \mathrm{p})[45,48]$. The exchange term of B3LYP consists of hybrid Hartree-Fock and local spin density (LSD) exchange functions with Becke's gradient correlation to LSD exchange [47, 49]. The correlation term of B3LYP consists of the Vosko, Wilk, Nusair (VWN3) local correlation functional [50] and Lee, Yang, Parr (LYP) correlation correction functional [51]. Also, the vibrational analyses have been done. The total electronic energies are corrected for the zero point vibrational energy (ZPE). The normal mode analysis for each structure yielded no imaginary frequencies for the $3 N-6$ vibrational degrees of freedom, where $N$ is the number of atoms in the system. This indicates that the structure of each molecule corresponds to at least a local minimum on the potential energy surface. All these calculations were done by using the Spartan 06 package program [52].

\section{Results and Discussion}

The presently considered composites are $\mathrm{FOX}-7+\mathrm{B}_{2} \mathrm{H}_{6}, \mathrm{FOX}-7+2 \mathrm{BH}_{3}$ and FOX$7+\mathrm{BH}_{3}$. It is to be mentioned that $\mathrm{BH}_{3}$ is the dissociation product (at least one of them) of $\mathrm{B}_{2} \mathrm{H}_{6}$. It is known that both $\mathrm{B}_{2} \mathrm{H}_{6}$ and $\mathrm{BH}_{3}$ are electron deficient reagents [7]. On the other hand FOX-7, also known as geminal diaminodinitroethene (DADNE), is a pushpull type olefinic compound classified as insensitive high explosive.

Figure 1 shows the optimized structures, as well as the direction of the dipole moments of the composites considered. As seen in the figure, diborane orients itself nearby one of the nitration groups of FOX-7 molecule. In the case of FOX-7+2 $\mathrm{BH}_{3}$ case, one of the borane molecules is around the nitro groups whereas the other borane 
molecule is nearby the amino groups. The $\mathrm{BH}_{3}$ molecule in the case of $1: 1$ composite locates itself next to the amino groups of FOX-7 molecule. All those variations of location of the $\mathrm{B}_{2} \mathrm{H}_{6}$ or $\mathrm{BH}_{3}$ molecules affect the properties of the composites. Some of the properties of the composites considered are displayed in Table 1.
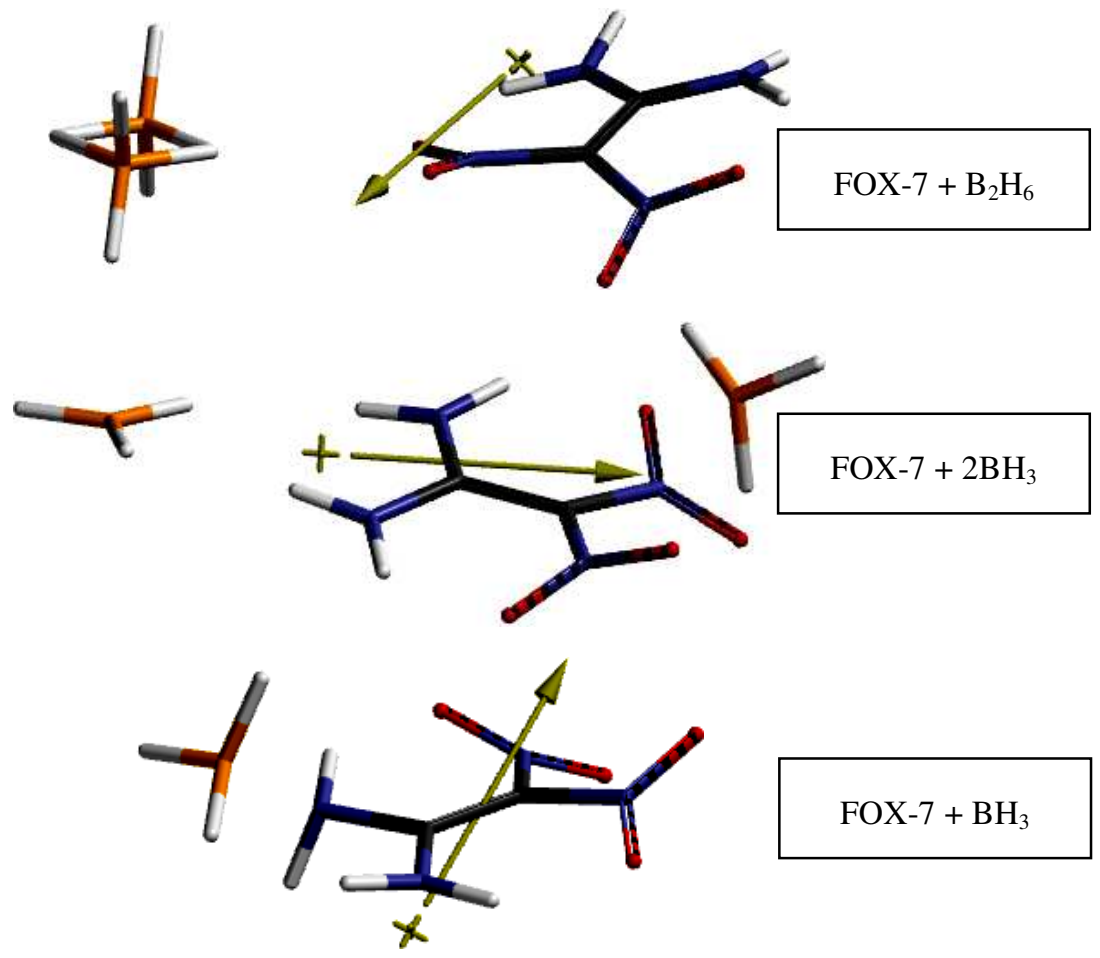

Figure 1. Optimized structures of the composites considered.

Table 1. Some properties of the composites considered.

\begin{tabular}{lccccc} 
Composite & $\begin{array}{c}\text { Dipole } \\
\text { moment }\end{array}$ & Polarizability & Hardness & Electronegativity & Ovality \\
\hline FOX-7 $+\mathrm{B}_{2} \mathrm{H}_{6}$ & 8.74 & 53.93 & 223.63 & 511.33 & 1.47 \\
$\mathrm{FOX}-7+2 \mathrm{BH}_{3}$ & 10.94 & 54.58 & 187.19 & 530.13 & 1.46 \\
$\mathrm{FOX}-7+\mathrm{BH}_{3}$ & 4.38 & 51.39 & 228.90 & 575.77 & 1.30 \\
\hline
\end{tabular}

Dipole moment in debye units. Hardness and electronegativity in $\mathrm{kJ} / \mathrm{mol}$. 
Figure 2 shows the ESP charges on the atoms of the composites. Note that the ESP charges are obtained by the program based on a numerical method that generates charges that reproduce the electrostatic potential field from the entire wavefunction [52]. In the diborane composite, the boron atoms acquire some partial negative charges contrary to the bridge hydrogens (three-centered bond owners).
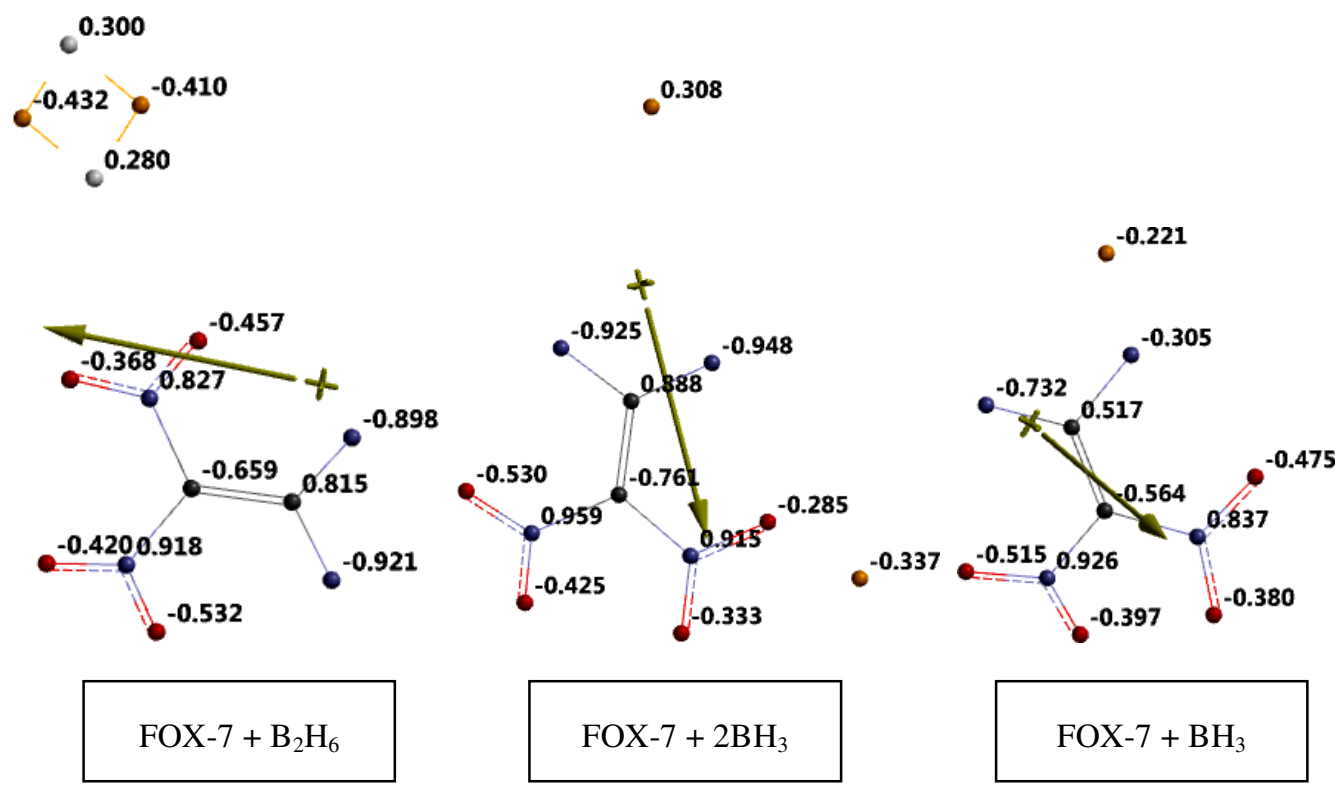

Figure 2. The ESP charges on the atoms of the composites (hydrogens of the threecentered bonds are omitted).

In the case of $\mathrm{FOX}-7+2 \mathrm{BH}_{3}$, the boron atom next to the amino groups has some positive partial charge whereas the other boron atom which is next to the $\mathrm{NO}_{2}$ group possesses negative partial charge. However, in $\mathrm{FOX}-7+\mathrm{BH}_{3}$ composite, the boron atom which is next to the amino groups has negative partial charge. In all the cases, the ESP charges on the respective atoms of the FOX-7 moieties are quite different from each other. These variations dictate the appearance of the electrostatic potential maps of the composites shown in Figure 3 where red/reddish and blue/ green regions stand for negative and positive potential fields, respectively.

Table 1 also shows the hardness and electronegativity values which are defined as;

$$
\text { Hardness }=-\left(\varepsilon_{\mathrm{HOMO}}-\varepsilon_{\mathrm{LUMO}}\right) / 2
$$

Electronegativity $=-\left(\varepsilon_{\mathrm{HOMO}}+\varepsilon_{\mathrm{LUMO}}\right) / 2$ 
where $\varepsilon_{\mathrm{HOMO}}$ and $\varepsilon_{\mathrm{LUMO}}$ are the energies of the highest occupied and lowest unoccupied molecular orbitals, respectively (see below paragraphs for the $\varepsilon_{\mathrm{HOMO}}$ and $\varepsilon_{\mathrm{LUMO}}$ values). The hardest and most electronegative composite is $\mathrm{FOX}-7+\mathrm{BH}_{3}$. FOX $-7+\mathrm{B}_{2} \mathrm{H}_{6}$ is harder but less electronegative than its isomeric composite.
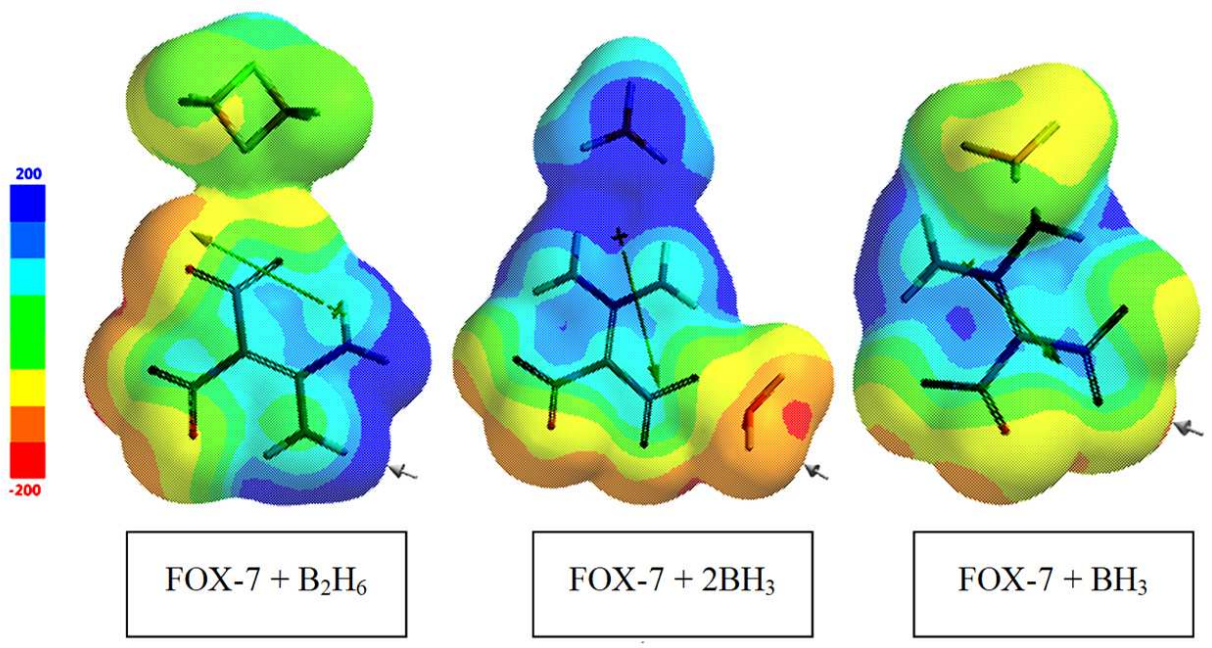

Figure 3. The electrostatic potential maps of the composites.

Table 2 shows some of the energies of the composites. Note that $\mathrm{FOX}-7+\mathrm{B}_{2} \mathrm{H}_{6}$ and FOX $-7+2 \mathrm{BH}_{3}$ composites have the same bruto formula, hence they are isomeric in some sense. The $\mathrm{E}, \mathrm{ZPE}$ and $\mathrm{E}_{\mathrm{C}}$ values are the total electronic energy, zero point vibrational energy and the corrected total electronic energy, respectively.

Table 2. Some energies of the composites considered.

\begin{tabular}{|c|c|c|c|}
\hline Composite & $\mathbf{E}$ & ZPE & $\mathbf{E}_{\mathbf{C}}$ \\
\hline $\mathrm{FOX}-7+\mathrm{B}_{2} \mathrm{H}_{6}$ & -1711339.67 & 407.88 & -1710931.79 \\
\hline $\mathrm{FOX}-7+2 \mathrm{BH}_{3}$ & -1711227.77 & 394.79 & -1710832.98 \\
\hline $\mathrm{FOX}-7+\mathrm{BH}_{3}$ & -1641332.54 & 330.06 & -1641002.48 \\
\hline
\end{tabular}

Energies in $\mathrm{kJ} / \mathrm{mol}$.

The comparison of $\mathrm{E}_{\mathrm{C}}$ values for the isomeric cases reveals that $\mathrm{FOX}-7+\mathrm{B}_{2} \mathrm{H}_{6}$ composite is electronically more stable than $\mathrm{FOX}-7+2 \mathrm{BH}_{3}$ case. It is also true for their 
thermal properties which are shown in Table 3 . The $\mathrm{H}^{\circ}$ values indicate that the formation of composite of $\mathrm{B}_{2} \mathrm{H}_{6}$ is more exothermic than the respective value of $\mathrm{FOX}-7+2 \mathrm{BH}_{3}$ case. Similarly, the free energy of formation values reveal that the formation of $\mathrm{B}_{2} \mathrm{H}_{6}$ composite is more favorable as compared to $\mathrm{FOX}-7+2 \mathrm{BH}_{3}$ case which is entropically more favored.

Table 3. Some thermo chemical energies of the composites considered.

\begin{tabular}{|c|c|c|c|}
\hline Composite & $\mathbf{H}^{\mathbf{o}}$ & $\mathbf{S}^{\mathrm{o}}\left(\mathrm{J} / \mathrm{mol}^{\mathrm{o}}\right)$ & $\mathbf{G}^{\mathbf{o}}$ \\
\hline $\mathrm{FOX}-7+\mathrm{B}_{2} \mathrm{H}_{6}$ & -1710914.01 & 442.46 & -1711045.93 \\
\hline $\mathrm{FOX}-7+2 \mathrm{BH}_{3}$ & -1710812.23 & 462.89 & -1710950.24 \\
\hline $\mathrm{FOX}-7+\mathrm{BH}_{3}$ & -1640990.06 & 397.96 & -1641108.71 \\
\hline
\end{tabular}

Energies in $\mathrm{kJ} / \mathrm{mol}$.

Table 4 shows the HOMO and LUMO energies as well as the interfrontier molecular orbital energy gaps $(\Delta \varepsilon)$ of the composites. The order of the HOMO energies is FOX$7+\mathrm{BH}_{3}<\mathrm{FOX}-7+\mathrm{B}_{2} \mathrm{H}_{6}<\mathrm{FOX}-7+2 \mathrm{BH}_{3}$. Whereas, the LUMO energies follow the order of $\mathrm{FOX}-7+\mathrm{BH}_{3}<\mathrm{FOX}-7+2 \mathrm{BH}_{3}<\mathrm{FOX}-7+\mathrm{B}_{2} \mathrm{H}_{6}$. As a consequence of these orders, the $\Delta \varepsilon$ values exhibit the order of FOX $-7+\mathrm{BH}_{3}<\mathrm{FOX}-7+\mathrm{B}_{2} \mathrm{H}_{6}<\mathrm{FOX}-7+2 \mathrm{BH}_{3}$. Table 4 also

Table 4. The HOMO, LUMO energies and the interfrontier molecular orbital energy gaps $(\Delta \varepsilon)$.

\begin{tabular}{lccc}
\hline Composite & HOMO & LUMO & $\Delta \boldsymbol{\varepsilon}$ \\
\hline FOX-7+B ${ }_{2} \mathrm{H}_{6}$ & -734.97 & -287.70 & 447.27 \\
$\mathrm{FOX}-7+2 \mathrm{BH}_{3}$ & -717.33 & -342.94 & 374.39 \\
$\mathrm{FOX}^{-7}+\mathrm{BH}_{3}$ & -804.68 & -346.87 & 457.81 \\
$\mathrm{~B}_{2} \mathrm{H}_{6}$ & -878.02 & -115.21 & 762.81 \\
$\mathrm{BH}_{3}$ & -940.81 & -216.69 & 724.12 \\
FOX-7 & -724.90 & -276.96 & 447.94 \\
\hline
\end{tabular}

Energies in $\mathrm{kJ} / \mathrm{mol}$. 
includes the respective energies of the components of the composites. The data in the table reveal that the composites have higher HOMO energy levels compared to the respective levels of the boron components but lower values with respect to FOX-7 component with the exception of $\mathrm{FOX}-7+2 \mathrm{BH}_{3}$. As for the LUMO energies, the composites all have lower values compared to their components. The composites all have smaller $\Delta \varepsilon$ values than that of the components.

Figure 4 shows some of the molecular orbital energy levels of the components of the composites. As seen in Table 4 and Figure 4, the HOMO and LUMO energy orders of the
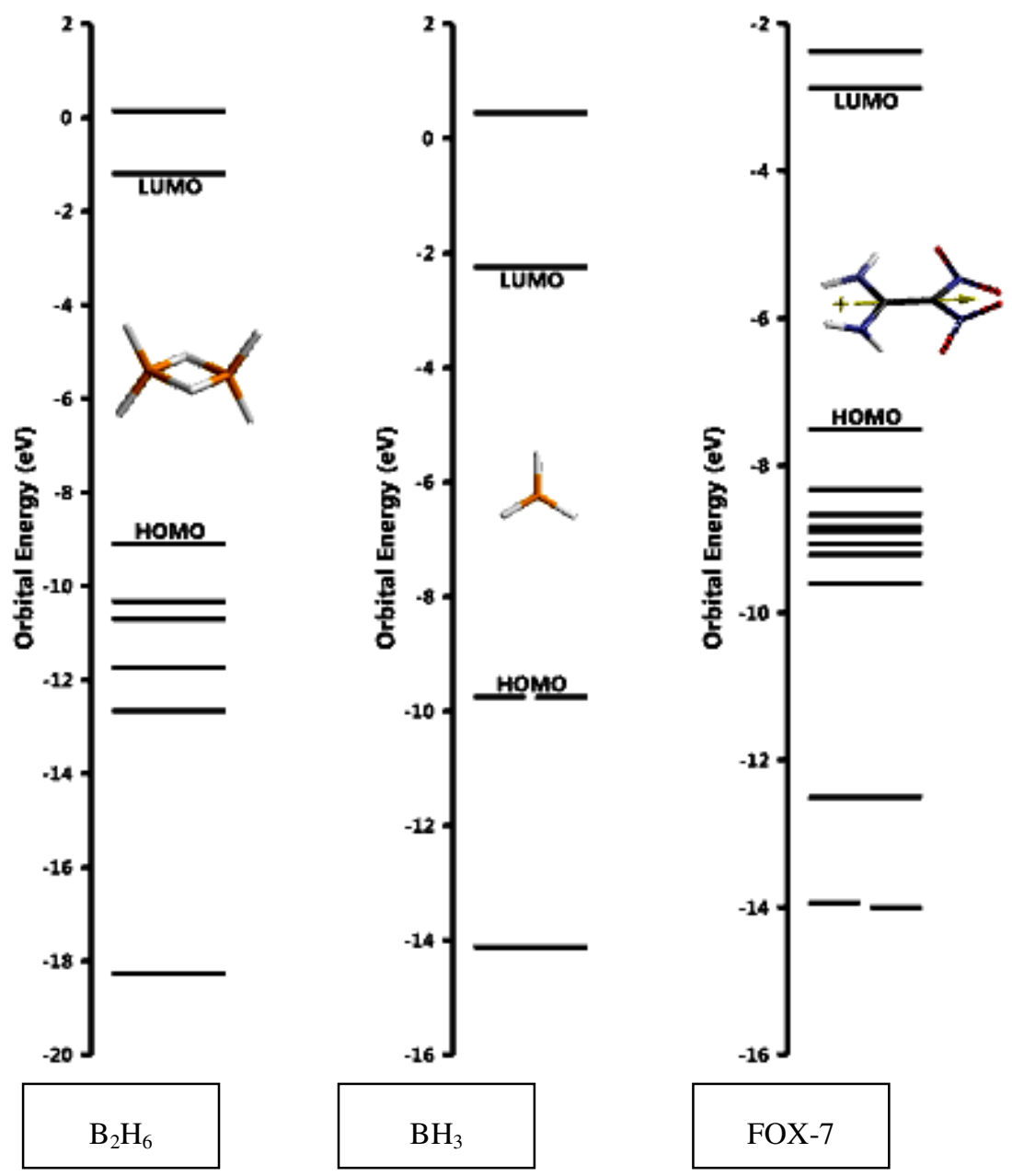

Figure 4. Some of the molecular orbital energy levels of the components of the composites. 
components is $\mathrm{BH}_{3}<\mathrm{B}_{2} \mathrm{H}_{6}<\mathrm{FOX}-7$ and FOX-7 $<\mathrm{BH}_{3}<\mathrm{B}_{2} \mathrm{H}_{6}$, respectively. The frontier molecular orbital interactions between the components as $\mathrm{LUMO}_{\mathrm{A}}-\mathrm{HOMO}_{\mathrm{B}}$ and $\mathrm{LUMO}_{\mathrm{B}}-\mathrm{HOMO}_{\mathrm{A}}$ are shown in Table 5. Accordingly, the interaction between FOX-7 and $\mathrm{B}_{2} \mathrm{H}_{6}$ seems to be almost equally $\mathrm{HOMO}_{\mathrm{B} 2 \mathrm{H} 6}-\mathrm{LUMO}_{\mathrm{FOX}-7}$ and $\mathrm{HOMO}_{\mathrm{FOX}-7^{-}}$ $\mathrm{LUMO}_{\mathrm{B} 2 \mathrm{H} 6}$ controlled. Whereas, the interaction with $\mathrm{BH}_{3}$ seems to be mainly $\mathrm{HOMO}_{\mathrm{FOX}-7-\mathrm{LUMO}_{\mathrm{BH} 3}}$ controlled.

Table 5. Type of frontier molecular orbital interactions between the components of the composites.

\begin{tabular}{lll}
\hline & HOMO (FOX-7) & LUMO (FOX-7) \\
\hline HOMO $\left(\mathrm{B}_{2} \mathrm{H}_{6}\right)$ & & 601.06 \\
LUMO $\left(\mathrm{B}_{2} \mathrm{H}_{6}\right)$ & 609.69 & \\
HOMO $\left(\mathrm{BH}_{3}\right)$ & & 663.85 \\
LUMO $\left(\mathrm{BH}_{3}\right)$ & 508.21 & \\
\hline
\end{tabular}

Energies in $\mathrm{kJ} / \mathrm{mol}$.

Figure 5 shows some of the molecular orbital energy levels of the composites considered. As seen in Table 4 and Figure 4 the dissociation of $\mathrm{B}_{2} \mathrm{H}_{6}$ into $\mathrm{BH}_{3}$ raises up the HOMO but lowers the LUMO levels of FOX-7+ $\mathrm{B}_{2} \mathrm{H}_{6}$ yielding molecular orbital energy levels of $\mathrm{FOX}-7+2 \mathrm{BH}_{3}$ composite. Meantime $\Delta \varepsilon$ values get smaller (narrowing of the interfrontier molecular orbital energy gap). Since $\Delta \varepsilon$ value of an explosive is associated with its sensitivity to impact $[53,54], \mathrm{FOX}-7+2 \mathrm{BH}_{3}$ composite should be more sensitive than the diborane composite. However, note that $\mathrm{BH}_{3}$ dimerizes at atmospheric pressure to yield diborane [55-57]. Also it is worth mentioning that the dissociation of $\mathrm{B}_{2} \mathrm{H}_{6}$ is not as simple as $\mathrm{B}_{2} \mathrm{H}_{6} \rightleftharpoons 2 \mathrm{BH}_{3}$. Some series of interconversions of the boronic species occur [7]. 

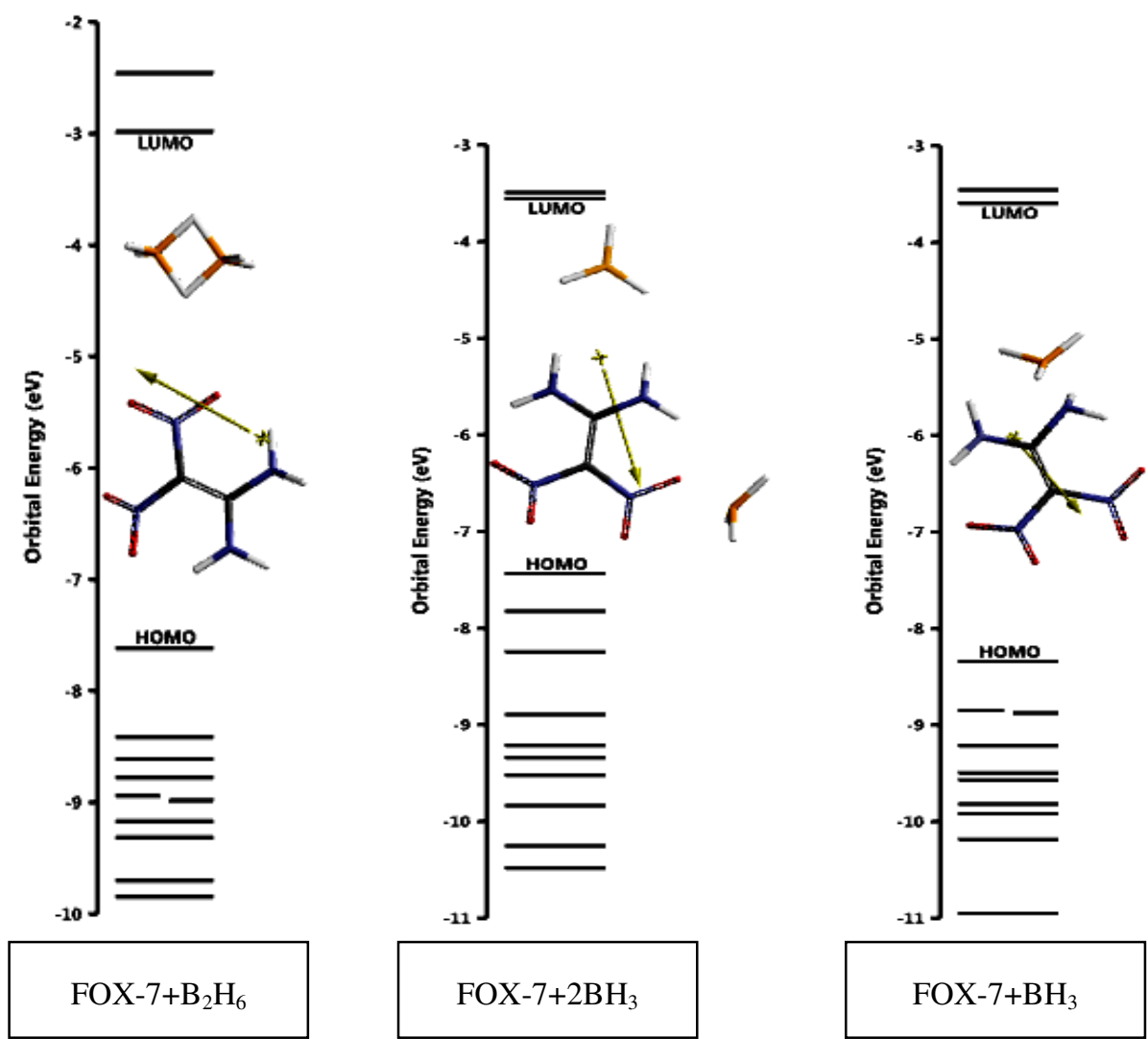

Figure 5. Some of the molecular orbital energy levels of the composite species considered.

Figure 6 shows the HOMO and LUMO patterns of the components of the composites. Whereas the respective patterns of the composites are shown in Figure 7.

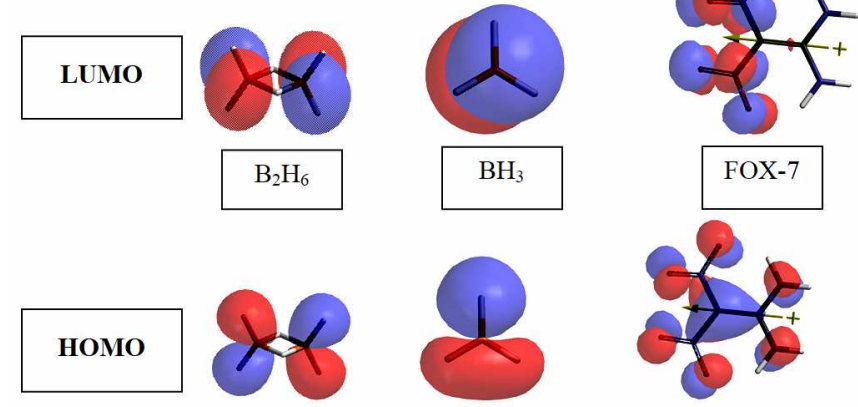

Figure 6. The HOMO and LUMO patterns of $\mathrm{B}_{2} \mathrm{H}_{6}, \mathrm{BH}_{3}$ and FOX-7. 


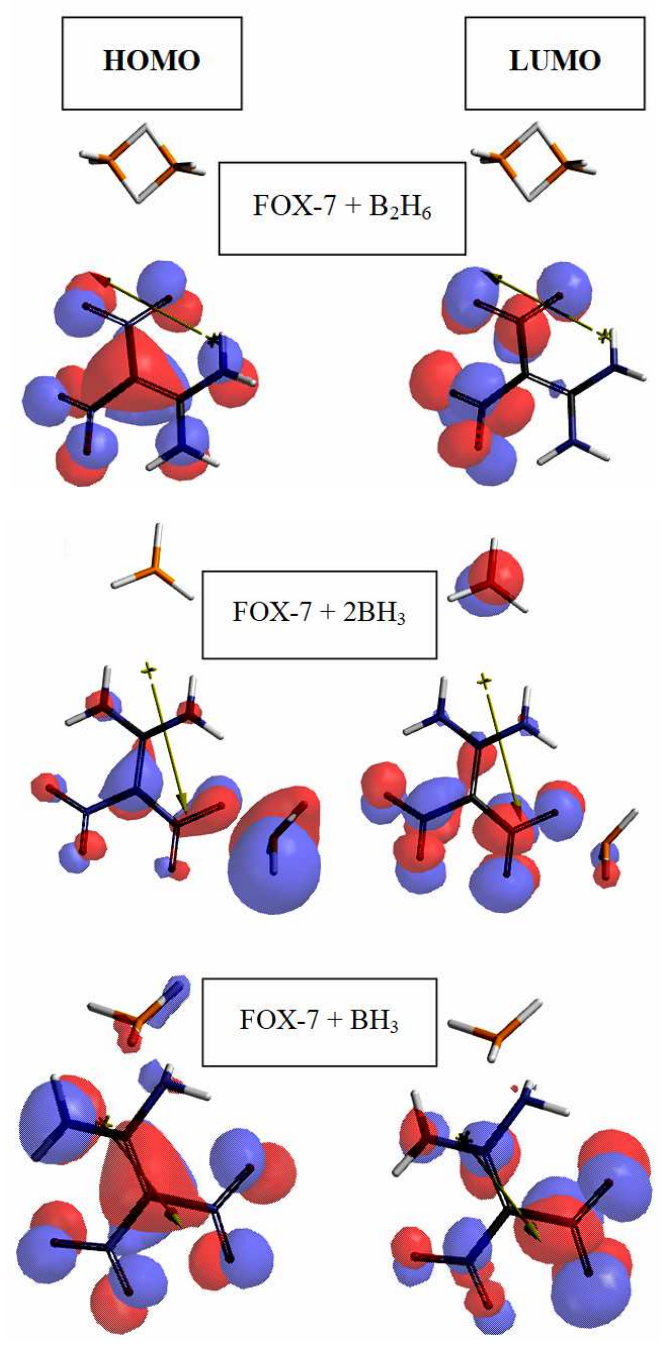

Figure 7. The HOMO and LUMO patterns of the composites considered.

Figure 7 shows that $\mathrm{B}_{2} \mathrm{H}_{6}$ molecule does not contribute either to HOMO or LUMO of the composite. In the case of $\mathrm{FOX}-7+2 \mathrm{BH}_{3}$ only one of the $\mathrm{BH}_{3}$ contributes into the HOMO of the composite but both of them into the LUMO of the composite. Whereas in FOX-7+ $\mathrm{BH}_{3}$ case $\mathrm{BH}_{3}$ contributes only into the HOMO. The comparison of the HOMO and LUMO patterns of FOX-7 with its patterns in the composites indicate that $\mathrm{B}_{2} \mathrm{H}_{6}$ does not affect the frontier molecular orbitals of the FOX-7 but in the other composites $\mathrm{BH}_{3}$ highly affects them. 
Figure 8 shows the LUMO maps of the composites. A LUMO map displays the absolute value of the LUMO on the electron density surface. The blue color stands for the maximum value of the LUMO and the color red, the minimum value. Hence, a nucleophile attacks on the atom having the blue color.
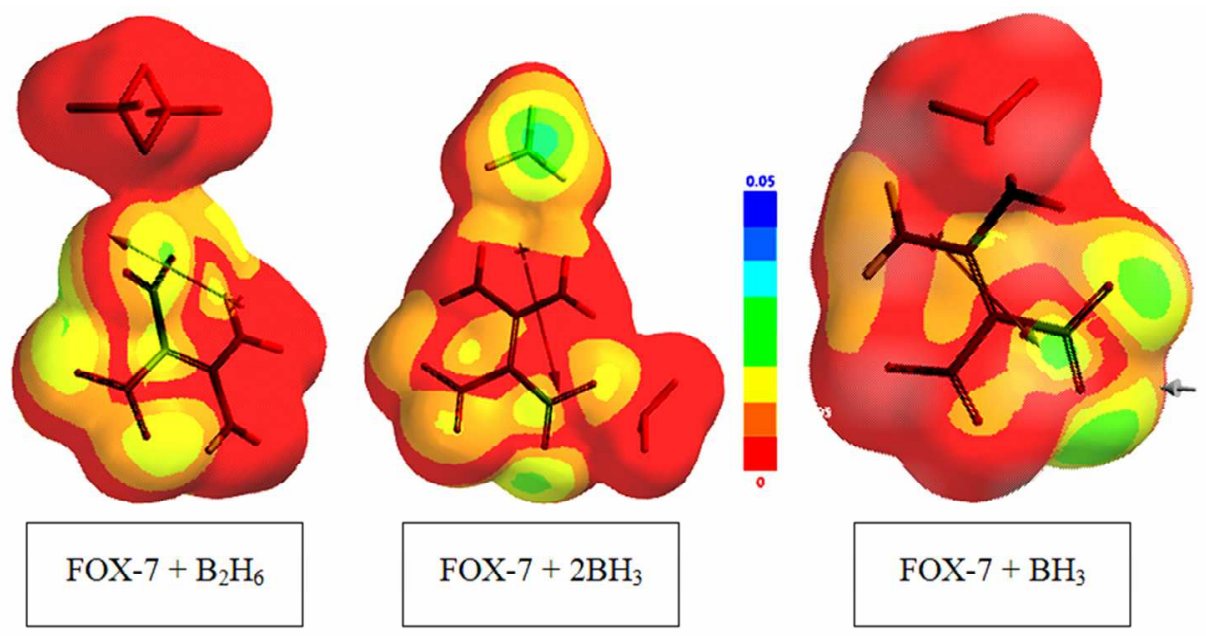

Figure 8. The LUMO maps of the composites.

\section{Conclusion}

Within the restrictions of the applied DFT methodology, the composites considered are found to be structurally stable and thermodynamically favorable although their components interact with each other. FOX $-7+\mathrm{B}_{2} \mathrm{H}_{6}$ composite is more stable than its isomeric composite $\mathrm{FOX}-7+2 \mathrm{BH}_{3}$. The later composite is characterized with higher HOMO but lower LUMO energy as compared to its isomeric one. Among the all, FOX$7+2 \mathrm{BH}_{3}$ has the smallest and $\mathrm{FOX}-7+\mathrm{BH}_{3}$ has the largest HOMO-LUMO energy gap. If the impact sensitivities are considered, and correlated with $\Delta \varepsilon$ values, as $\mathrm{B}_{2} \mathrm{H}_{6}$ in the composite undergoes dissociation, increasing number of $\mathrm{BH}_{3}$ molecules should turn the composite to be more and more sensitive to impact.

\section{References}

[1] G. Parkin, Representation of three-center-two-electron bonds in covalent molecules with bridging hydrogen atoms, J. Chem. Educ. 96(11) (2019), 2467-2475. https://doi.org/10.1021/acs.jchemed.9b00750 
[2] P.J. Durant and B. Durant, Introduction to Advanced Inorganic Chemistry, London: Longman, 1972.

[3] H.D. Francesco, J. Dudley and A. Coca, Boron Chemistry: An Overview, ACS Symposium Series 1236 (2016), 1-25. https://doi.org/10.1021/bk-2016-1236.ch001

[4] Q. Zhao, J. Li, E.J.M. Hamilton and X. Chen, The continuing story of the diammoniate of diborane, J. Organomet. Chem. 798(1) (2015), 24-29.

https://doi.org/10.1016/j.jorganchem.2015.05.027

[5] T.P. Fehlner, Reactions of borane $\left(\mathrm{BH}_{3}\right)$. VI. Reactions with alcohols, Inorg. Chem. 12(1) (1973), 98-102. https://doi.org/10.1021/ic50119a025

[6] T. Onak, Organoboran Chemistry, NY: Academic Press, 1975. https://doi.org/10.1016/B978-0-12-526550-8.50009-5

[7] K. Wade, Electron Deficient Compounds, London: Nelson, 1971. https://doi.org/10.1007/978-1-4684-6054-4

[8] P. Laszlo, A diborane story, Angewandte Chemie International Edition 39(12) (2000), 2071-2072. doi:10.1002/1521-3773(20000616)39:12<2071::aid-anie2071>3.0.co;2-c.

[9] S.H. Bauer, Energetics of the boranes. II. Kinetic consequences of the diborane-borane equilibrium. Comments on the decomposition of $\mathrm{OC}: \mathrm{BH}_{3}, \mathrm{~J}$. Am. Chem. Soc. 78(22) (1956), 5775-5782. https://doi.org/10.1021/ja01603a017

[10] C. Edmiston and P. Lindner, On the dimerization of $\mathrm{BH}_{3}$ and the associated delocalization (resonance) energy, Int. J. Quantum Chem. 7(2) (1973), 309-318.

https://doi.org/10.1002/qua.560070213

[11] X. Wang, Y. Li, Y. D. Wu, M.N. Paddon-Row, N.G. Rondan and K.N. Houk, Ab initio transition structures for hydroborations of alkenes, allenes, and alkynes by borane, diborane, methylborane, methylfluoroborane, and dimethylborane, J. Org. Chem. 55(9) (1990), 2601-2609. https://doi.org/10.1021/jo00296a013

[12] R. Liao, Interpreting the electronic structure of the hydrogen-bridge bond in $\mathrm{B}_{2} \mathrm{H}_{6}$ through a hypothetical reaction, Struct. Chem. 23 (2012), 525-527.

https://doi.org/10.1007/s11224-011-9877-x

[13] R.J. Brotherton and H. Steinberg, Progress in Boron Chemistry, V 2 and 3, Amsterdam: Elsevier, 2016.

[14] V.N. Huff, C.S. Calvert and V.C. Erdmann, Theoretical Performance of Diborane as a Rocket Fuel, NACA research memorandum, National Advisory Committee for Aeronautics research memorandum, National Advisory Committee for Aeronautics, NACA RM. No. E8I17a, Washington, 1949. 
[15] R.A. Carpenter, Liquid rocket propellants: Fuels and oxidizers of the future, Ind. Eng. Chem. 49 (1957), 42A-48A. https://doi.org/10.1021/i650568a731

[16] R.A. Carpenter, Recent advances in boron technology, ARS J. 29 (1959), 8-14.

[17] D.R. Martin, The development of borane fuels, J. Chem. Educ. 36 (1959), 208-214. https://doi.org/10.1021/ed036p208

[18] E.A. Weilmuenster, Utilization of high-energy fuel elements, Ind. Eng. Chem. 49 (1957), 1337-1338. https://doi.org/10.1021/ie50573a020

[19] J.P. Agrawal, High Energy Materials, Weinheim: Wiley-VCH, 2010. https://doi.org/10.1002/9783527628803

[20] P. Politzer and J.S. Murray, Energetic Materials, Part 1, Amsterdam: Elsevier, 2003.

[21] I.J. Lochert, FOX-7 - A New Insensitive Explosive, DSTO Aeronautical and Maritime Research Laboratory, 506 Lorimer St, Fishermans Bend, Victoria 3207 Australia, AR012-065, November 2001.

[22] N.V. Latypov, J. Bergman, A. Langlet, U. Wellmar and U. Bemm, Synthesis and reactions of 1,1-diamino-2,2-dinitroethylene, Tetrahedron 54 (1998), 11525-11536. https://doi.org/10.1016/S0040-4020(98)00673-5

[23] U. Bemm and H. Östmark, 1,1-Diamino-2,2-dinitroethylene: A novel energetic material with infinite layers in two dimensions, Acta Crystallogr. C 54 (1998), 1997-1999. https://doi.org/10.1107/S0108270198007987

[24] N.V. Latypov, A. Langlet and U. Wellmar, New chemical compound suitable for use as an explosive, intermediate and method for preparing the compound, Patent WO99/03818, 1999.

[25] H. Östmark, H. Bergman, U. Bemm, P. Goede, E. Holmgren, M. Johansson, A. Langlet, NV. Latypov, A. Petterson, ML. Petterson, N. Wingborg, C. Vörde, H. Stenmark, L. Karlsson and M. Hihkiö, 2,2-dinitro-ethene-1,1-diamine (FOX-7) - Properties, analysis and scale-up, $32^{\text {nd }}$ International Annual Conference of ICT on Energetic MaterialsIgnition, Combustion and Detonation, Karlsruhe, Germany, 2001.

[26] H. Östmark, A. Langlet, H. Bergman, N. Wingborg, U. Wellmar and U. Bemm, FOX-7A new explosive with low sensitivity and high performance, The 11th International Detonation Symposium, Colorado, USA, 1998.

[27] H. Bergman, H. Ostmark, A. Pettersson, M.L. Petterson, U. Bemm and M. Hihkio, Some Initial properties and thermal stability of FOX-7, Insensitive Munitions and Energetic Materials Symposium (NDIA), Tampa, Florida, USA, 1999. 
[28] W.A. Trzciński and A. Belaada, 1,1-Diamino-2,2-dinitroethene (DADNE, FOX-7) Properties and formulations (a Review), Cent. Eur. J. Energ. Mater. 13(2) (2016), 527544. https://doi.org/10.22211/cejem/65000

[29] B. Janzon, H. Bergman, C. Eldsater, C. Lamnevik and H. Ostmark, FOX-7 - A novel, high performance, low vulnerability high explosive for warhead applications, 20th Int. Symp. Ballistics, Orlando, Florida, USA: September 23-27, 2002.

[30] Y.N. Matyushin, G.T. Afanas'ev, V.P. Lebedev, M.N. Mahov and V.I. Pepekin, TATB and FOX-7: Thermochemistry, performance, detonability, sensitivity, 34th Int. Annu. Conf. ICT, Karlsruhe, Germany: June 24-27, 2003.

[31] AJ. Bellamy, NV. Latypov and P. Goede, Studies on the nitration of new potential precursors for FOX-7, New Trends Res. Energ. Mater. Proc. Semin. 7th, Pardubice, Czech Republic: April 20-22, 2004.

[32] S. Cudziło, Z. Chyłek and R. Diduszko, Crystallization and characterization of 1,1diamino-2,2-dinitroethene (DADNE), 36th Int. Annu. Conf. ICT, Karlsruhe, Germany: June 28-July 1, 2005.

[33] W.A. Trzciński, S. Cudziło, Z. Chyłek and L. Szymańczyk, Investigation of sensitivity and detonation properties of FOX-7, 37th Int. Annu. Conf. ICT, Karlsruhe, Germany: June 27-30, 2006.

[34] M. Anniyappan, M.B. Talawar, G.M. Gore, S. Venugopalan and B.R. Gandhe, Synthesis, characterization and thermolysis of 1,1-diamino-2,2-dinitroethylene (FOX-7) and its salts, J. Hazard. Mater. B 137 (2006), 812-819. https://doi.org/10.1016/j.jhazmat.2006.03.034

[35] W.A. Trzciński, S. Cudziło, Z. Chyłek and L. Szymańczyk, Detonation properties of 1,1diamino-2,2-dinitroethene (DADNE), J. Hazard. Mater. 157 (2008), 605-612. https://doi.org/10.1016/j.jhazmat.2008.01.026

[36] V.S. Mishra, S.R. Vadali, R.K. Garg, V.S. Joshi, R.D. Wasnik and S. Asthana, Studies on FOX-7 based melt cast high explosive formulations, Cent. Eur. J. Energ. Mater. 10(4) (2013), 569-580.

[37] N.V. Latypov, M. Johansson, E. Holmgren, E.V. Sizova, V.V. Sizov and A.J. Bellamy, On the synthesis of 1,1-diamino-2,2-dinitroethene (FOX-7) by nitration of 4,6-dihydroxy2-methylpyrimidine, Org. Process Res. Dev. 11(1) (2007), 56-59.

https://doi.org/10.1021/op068010t.

[38] Y. Zhang, Q. Sun, K. Xu, J. Song and F. Zhao, Review on the reactivity of 1,1-diamino2,2-dinitroethylene (FOX-7), Propellants Explos. Pyrotech. 41 (2016), 35-52. https://doi.org/10.1002/prep.201500065 
[39] K. Baum, N.V. Nguyen, R. Gilardi, J.L. Flippen-Anderson and C. George, Nitration of 1,1-diamino-2,2-dinitroethylenes, J. Org. Chem. 57 (1992), 3026-3030. https://doi.org/10.1021/jo00037a015

[40] T.M. Klapötke, Chemistry of High-Energy Materials, Berlin: De Gruyter, 2011. https://doi.org/10.1515/9783110227840

[41] H. Lips and K. Menke, FOX-7/GAP rocket propellants for a shoulder launched projectile, 27th International Symposium on Ballistics, Freiburg, Germany: April 22-26, 2013.

[42] J.J.P. Stewart, Optimization of parameters for semiempirical methods I. Method, J. Comput. Chem. 10 (1989), 209-220. https://doi.org/10.1002/jcc.540100208

[43] J.J.P. Stewart, Optimization of parameters for semi empirical methods II. Application, $J$. Comput. Chem., 10 (1989), 221-264. https://doi.org/10.1002/jcc.540100209

[44] A.R. Leach, Molecular Modeling, Essex: Longman, 1997.

[45] P. Fletcher, Practical Methods of Optimization, New York: Wiley, 1990.

[46] W. Kohn and L. Sham, Self-consistent equations including exchange and correlation effects, J. Phys. Rev. 140 (1965), 1133-1138. https://doi.org/10.1103/PhysRev.140.A1133

[47] R.G. Parr and W. Yang, Density Functional Theory of Atoms and Molecules, London: Oxford University Press, 1989.

[48] C.J. Cramer, Essentials of Computational Chemistry, Chichester, West Sussex: Wiley, 2004.

[49] A.D. Becke, Density-functional exchange-energy approximation with correct asymptotic behavior, Phys. Rev. A 38 (1988), 3098-3100. https://doi.org/10.1103/PhysRevA.38.3098

[50] S.H. Vosko, L. Wilk and M. Nusair, Accurate spin-dependent electron liquid correlation energies for local spin density calculations: a critical analysis, Can. J. Phys. 58 (1980), 1200-1211. https://doi.org/10.1139/p80-159

[51] C. Lee, W. Yang and R.G. Parr, Development of the Colle-Salvetti correlation-energy formula into a functional of the electron density, Phys. Rev. B 37 (1988), 785-789. https://doi.org/10.1103/PhysRevB.37.785

[52] SPARTAN 06, Wavefunction Inc., Irvine CA, USA, 2006.

[53] V. Anbu, K.A. Vijayalakshmi, R. Karunathan, A. David Stephen and P.V. Nidhin, Explosives properties of high energetic trinitrophenyl nitramide molecules: A DFT and AIM analysis, Arabian J. Chem. 12(5) (2019), 621-632.

https://doi.org/10.1016/j.arabjc.2016.09.023 
[54] N.R. Badders, C. Wei, A.A. Aldeeb, W.J. Rogers and M.S. Mannan, Predicting the impact sensitivities of polynitro compounds using quantum chemical descriptors, $J$. Energ. Mater. 24 (2006), 17-33. https://doi.org/10.1080/07370650500374326

[55] L.H. Long, The mechanisms of thermal decomposition of diborane and of interconversion of the boranes: a reinterpretation of the evidence, J. Inorg. Nucl. Chem. 32(4) (1970), 1097-1115. https://doi.org/10.1016/0022-1902(70)80104-X

[56] Y.B. Fan, Z.B. Ding, Q.R. Wang and F.G. Tao, A DFT study on dissociation of diborane $\left(\mathrm{B}_{2} \mathrm{H}_{6}\right)$ in dimethyl sulfide media, Chem. Phys. Lett. 328(1-2) (2000), 39-44. https://doi.org/10.1016/S0009-2614(00)00886-1

[57] G.G. Hawley, The Condensed Chemical Dictionary, 9th ed., NY: Van Nostrand Reinhold, 1977. 